\title{
O PACTO NACIONAL PELO FORTALECIMENTO DO ENSINO MÉDIO: LIMITES E POSSIBILIDADES DA FORMAÇÃO E ATUAÇÃO DOCENTE NO CAMPO DA EDUCAÇÃO INCLUSIVA
}

http://dx.doi.org/10.5902/2318133818865

\author{
Karlane Holanda Araújo \\ Universidade Federal do Ceará, Brasil. \\ José Melinho de Lima Neto \\ Universidade Federal do Ceará, Brasil.
}

\begin{abstract}
Resumo
A ausência do campo temático da educação inclusiva nos cadernos de formação de professores do Pacto Nacional pelo Fortalecimento do Ensino Médio foi suficiente para gerar inquietações, reflexões e o desejo de realizar um estudo teórico, com o objetivo de analisar o alcance dos fundamentos legais da política de educação especial na perspectiva inclusiva, confrontando com as possibilidades e os limites da formação e atuação do trabalho docente no ensino médio propostos no referido pacto. A inclusão de alunos com necessidades especiais no sistema regular de ensino é hoje a diretriz principal das políticas públicas educacionais, tanto a nível federal, quanto estadual e municipal. Então, como justificar a criação de um programa nacional de formação docente para os professores do ensino médio sem levar em consideração o currículo e as práticas de ensino na perspectiva da educação inclusiva? Não seria um paradoxo lançar um pacto pelo fortalecimento do ensino médio excluindo dos encontros, estudos e trocas de experiências entre professores os preceitos básicos a respeito da educação inclusiva? Cada vez mais as escolas recebem alunos com necessidades educativas especiais e sua inclusão nas classes regulares de ensino médio, sem a devida qualificação profissional docente, tende a aumentar os indicadores de evasão, distorção idade-série e reprovação escolar, agravando o quadro de exclusão escolar e, consequentemente, de discriminação social. Não se pode fazer inclusão quando não se consegue sequer incluir no programa de formação docente o campo temático da educação inclusiva. Nesse sentido, com este artigo, espera-se trazer à tona a discussão sobre a exclusão do tema da educação inclusiva no programa de formação de professores do Pacto Nacional pelo Fortalecimento do Ensino Médio e propor a inclusão, em caráter especial, da educação inclusiva como campo temático, sugerindo a produção de um caderno complementar para esse fim.

Palavras-chave: educação inclusiva, formação de professores, exclusão.
\end{abstract}




\title{
THE NATIONAL PACT TO STRENGTHENING THE SECONDARY EDUCATION: LIMITS AND POSSIBILITIES TO FORMATION AND ACTING OF TEACHER IN INCLUSIVE EDUCATION AREA
}

\begin{abstract}
The absence of Inclusive Education thematic field in Teacher's Education Program of the Pact for Secondary Schooling Strengthening was enough to generate concerns, thinking and the will to start a theoretic study aimed at analyzing the range of Legal fundaments for special education politics on an inclusive perspective. Confronting this perspective with the possibilities and boundaries of teaching training/making in secondary school as proposed in the referred Pact. Inclusion of students with special needs in regular educational system is, nowadays, the main directive on educational public politics in federal, state and municipalities programs. Thus, how is it possible to create a national program for secondary schools teachers' training not taking into consideration the curriculum and teaching practices in an inclusive education perspective? Would it not seem a paradox to start such a Pact for strengthening secondary schooling, excluding the basic principles of inclusive education from the studies and experiences exchanges that take place in teachers training? More and more students with special needs are enrolling at regular schools, and their placement in regular classes, without the necessary teaching qualifications, tend to increase the evasion rates and the age - grade distortion and failure; aggravating the exclusion pictures at schools; and thus, of social discrimination. One cannot promote social integration, if do not, cannot, also include in teachers training, the thematic field of inclusive education. Seen in these terms, it is expected in this paper, to bring up a discussion on inclusive education in teacher's training program of Pact for Strengthening Secondary Schooling; proposing the insertion, in particular, of inclusive education as a thematic field, also suggesting the development of complementary material to that end.

Key-words: inclusive education, teachers training, exclusion.
\end{abstract}




\section{Introdução}

este artigo aborda-se o Pacto Nacional pelo Fortalecimento do Ensino Médio

N e sua relação com os desafios de inserir o campo temático da educação inclusiva na formação de professores. $O$ interesse por esse assunto surgiu durante os encontros relacionados ao referido pacto no Estado do Ceará, devido à presença constante de questionamentos por parte dos educadores envolvidos sobre as limitações do debate na seara da educação inclusiva, bem como dos conhecimentos adquiridos na formação profissional.

O Pacto Nacional pelo Fortalecimento do Ensino Médio é um programa do governo federal instituído por meio da portaria n. 1.140, de 22 de novembro de 2013, e representa a articulação e a coordenação de ações e estratégias entre a União e os governos estaduais e distrital na formulação e implantação de políticas para elevar o padrão de qualidade do ensino médio brasileiro, em suas diferentes modalidades, orientado pela perspectiva de inclusão. Tal política encontra-se em consonância com a lei n. 9.394, de 1996, e com as diretrizes curriculares nacionais para o ensino médio, instituídas na resolução n. 2 do Conselho Nacional de Educação e da Câmara de Educação Básica CNE/CEB -, de 30 de janeiro de 2012.

Essa articulação que envolve professores e coordenadores acontece em serviço, com encontros sistemáticos na própria escola, os quais são mediados pelo orientador de estudos. O curso compreende uma carga horária de três horas semanais da jornada de trabalho destinadas para estudos, reflexões e discussões, com o objetivo de favorecer o aprimoramento profissional, contabilizando um total de 200 horas aulas distribuídas em atividades individuais e coletivas (Brasil, 2014a):

O curso privilegia a articulação entre a teoria e a prática no processo de formação docente, fundado no domínio de conhecimentos científicos e didáticos. Considera a escola como lócus de formação continuada e (re)construção coletiva do projeto político-pedagógico. (p. 5)

O professor, como sendo um sujeito ativo no processo de capacitação, é compreendido pela concepção de formação continuada da proposta do curso, que busca atualização e aprofundamento do conhecimento, como também elabora e produz conhecimentos com base na compreensão da realidade e nas possibilidades de transformação da sociedade.

Os encontros propostos por meio do pacto, realizados no ambiente escolar, e as temáticas contidas nos cadernos $^{1}$ de formação do professor não contemplam o tema específico da educação inclusiva. Tal situação suscita dúvidas entre os professores envolvidos, levantando questões quanto às lacunas existentes entre o discurso e a aplicabilidade das leis no campo da educação inclusiva, fomentando, assim, debates e discussões em volta de experiências vivenciadas. Esses questionamentos são procedentes do cotidiano escolar cearense, no qual é comum a presença de alunos com

\footnotetext{
${ }^{1}$ Cadernos de formação do professor: material didático do Pacto Nacional pelo Fortalecimento do Ensino Médio, composto por dez cadernos, sendo cinco destinados à etapa I, que aborda os campos temáticos: Ensino médio e formação humana integral, O jovem como sujeito do ensino médio, Currículo do ensino, seus sujeitos e o desafio da formação humana integral, Área de conhecimento e integração curricular, Organização e gestão democrática da escola; e mais cinco cadernos para a etapa II, que aborda: A organização do trabalho pedagógico no ensino médio, Ciências humanas, Ciências da natureza, Linguagens e Matemática. 
deficiência auditiva, visual e intelectual. Assim, busca-se seguir as diretrizes legais ao efetuar a matrícula nas classes de ensino médio regular, gerando para os professores exigências de formação e condições de trabalho desafiadoras.

Para oferecer uma educação de qualidade para todos, inclusive para os portadores de necessidades especiais, a escola precisa capacitar seus professores, preparar-se, organizar-se, enfim, adaptar-se. Inclusão não significa, simplesmente, matricular os discentes com necessidades especiais na classe comum, ignorando suas necessidades específicas, mas significa dar ao docente e à escola o suporte necessário à sua ação pedagógica (Brasil, 1994b).

Conforme Garcia (2013) a política de educação especial no Brasil, na última década, ganhou contornos que merecem ser analisados por conta de suas mudanças conceituais e estruturais. Parte desse movimento está relacionada à adoção de uma perspectiva inclusiva para a educação nacional, que ganhou definições particulares quando voltada aos sujeitos que constituem o público-alvo das políticas de educação especial. Tais sujeitos estão definidos no âmbito da política nacional como aqueles "com deficiência, transtornos globais de desenvolvimento e altas habilidades/superdotação" (Brasil, 2008, p. 15).

A população com necessidades educativas especiais é aquela que possui evidentes traços que a põem em situação diferente da população em geral. No entanto, esses traços não são os maiores determinantes de seu sucesso ou fracasso escolar, mas sim a qualidade do trabalho pedagógico realizado. Para essa população faz-se necessário um trabalho pedagógico diversificado, na perspectiva de que o conhecimento da diferença seja integrado, numa compreensão da diversidade humana que vai além das altas habilidades e da deficiência, que possibilite, ao mesmo tempo, a confrontação dessas diferentes manifestações e o acesso à cultura universal.

Não obstante, para que isso aconteça, várias ações são indispensáveis, como a qualidade da formação do corpo docente e o acesso aos recursos estruturais escolares que possam atender a contento à população com necessidades especiais, assim como formação docente.

De acordo com o Plano Nacional de Educação a formação de recursos humanos com capacidade de oferecer $\mathrm{o}$ atendimento aos educandos especiais nas creches, préescolas, centros de educação infantil, escolas regulares de ensino fundamental, médio e superior, bem como em instituições especializadas e outras instituições, é uma prioridade: "Não há como ter uma escola regular eficaz quanto ao desenvolvimento e aprendizagem dos educandos especiais sem que professores, demais técnicos, pessoal administrativo e auxiliar sejam preparados para atendê-los adequadamente" (Brasil, 2000, p. 87).

Partindo do referencial filosófico presente na Política Nacional de Educação Especial na Perspectiva Inclusiva (2008), numa sociedade democrática espera-se como função da educação proporcionar condições para que todos os alunos desenvolvam suas capacidades, respeitando-se suas diferenças, preparando-os para o exercício da cidadania: 
A educação inclusiva constitui um paradigma educacional fundamentado na concepção de direitos humanos, que conjuga igualdade e diferença como valores indissociáveis, e que avança em relação à idéia de eqüidade formal ao contextualizar as circunstâncias históricas da produção da exclusão dentro e fora da escola. (Brasil, 2008, p. 5)

Nesse sentido, a Política Nacional de Educação Especial na Perspectiva Inclusiva propõe a superação do modelo tradicional de educação escolar, vigente até os dias atuais, que tende a segregar os estudantes perante 0 conceito de normalidade/anormalidade, em razão das características intelectuais, físicas, culturais, sociais e linguísticas, "excluindo indivíduos e grupos considerados fora dos padrões homogeneizadores da escola" (Brasil, 2008, p. 6).

Para superar tal modelo, registra-se a necessidade da atenção dedicada ao preparo e à formação docente, anunciada e eleita como uma das prioridades da educação desde o ano 2000, no primeiro Plano Nacional de Educação:

Valorização dos profissionais da educação. Particular atenção deverá ser dada à formação inicial e continuada, em especial dos professores. Faz parte dessa valorização a garantia das condições adequadas de trabalho, entre elas o tempo para estudo e preparação das aulas, salário digno, com piso salarial e carreira de magistério. (Brasil, 2000, p. 35)

No caso da política de formação dos professores, pelo Pacto Nacional pelo Fortalecimento do Ensino Médio, há o registro de abrangência de 20.317 escolas e 495.697 professores para um universo de sete milhões de estudantes. Conta ainda com o apoio de 40 universidades brasileiras envolvidas no processo de formação docente. Segundo o Ministério da Educação o orçamento destinado para esse programa se encontra na ordem de um bilhão de reais. A formação continuada de professores e coordenadores pedagógicos do ensino médio contempla o pagamento de bolsas de estudo e pesquisa com repasse de $\mathrm{R} \$ 200,00$ mensais, durante dez meses, para todos os professores que estão em efetivo exercício (Brasil, 2014a).

Diante dessas informações pode-se considerar que esse é um programa de grande magnitude, configurando-se como uma política de mobilização nacional de formação dos professores do ensino médio sem precedentes na história da educação brasileira. Então, por que o campo temático da educação inclusiva não foi contemplado nos cadernos de formação do professor? Não seria um paradoxo lançar um pacto pelo fortalecimento do ensino médio excluindo dos encontros, estudos e trocas de experiências entre professores os preceitos básicos a respeito da educação inclusiva? Como justificar a criação de um programa nacional de formação docente para os professores do ensino médio sem levar em consideração o currículo e as práticas de ensino na perspectiva da educação inclusiva?

Segundo dados contidos no Anuário brasileiro da educação básica (Cruz; Monteiro, 2013), o número de alunos incluídos em classes comuns no ensino médio vem crescendo consideravelmente. Em 2007 havia 13.306 estudantes incluídos, sendo que, em 2011, houve um significativo aumento, indo para 33.138 alunos incluídos. Essa realidade justifica a necessidade emergente da inserção desse campo temático no material didático do pacto e nos encontros de capacitação e formação de professores, visto que, cada vez mais, as escolas recebem aprendizes com necessidades educativas especiais e sua 
inclusão nas classes regulares de ensino médio, sem a devida qualificação profissional docente, tende a aumentar os indicadores de evasão, distorção idade-série e reprovação escolar, agravando o quadro de exclusão escolar e,consequentemente, de discriminação social:

As crianças e jovens com necessidades educativas especiais devem ter acesso às escolas regulares, que a elas devem se adequar [...], pois tais escolas constituem os meios mais capazes para combater as atitudes discriminatórias, construindo uma sociedade inclusiva e atingindo a educação para todos. (Unesco, 1994, p. 8)

Nesse sentido espera-se, com este artigo, trazer à tona a discussão sobre a relevância da inserção do campo temático da educação inclusiva no programa de formação de professores do Pacto Nacional pelo Fortalecimento do Ensino Médio.

\section{A política nacional de educação especial na perspectiva inclusiva: marco legal}

Uma série de documentos internacionais - Programa de Ação Mundial para as Pessoas Deficientes (1982), Declaração Mundial sobre Educação para Todos (1990) e, em especial, Declaração de Salamanca (1994) - tem orientado a adoção de políticas públicas inclusivas no Brasil.

Esse movimento tem sido planejado mundialmente a partir de uma série de congressos, conferências e similares, organizados pela Organização das Nações Unidas por meio da Unesco, Unicef, Pnud, entre outros, com o patrocínio do Banco Mundial, do Fundo Monetário Internacional. Nesses eventos são produzidos documentos que, sob a forma de declaração, orientação, programas e planos de ação mundial, servem como vetores de orientação para a definição de políticas educacionais.

A educação para todos, como política educacional planetária, tem como mote a proposta de desenvolvimento humano, objetivo maior a ser alcançado e para o qual convergem as propostas e orientações. A EPT já estava desenhada no Programa de Ação Mundial (1982), porém, nos anos 1990 ganhou força a proposta original do Banco Mundial de dar ênfase à escola primária, centrada na satisfação das necessidades básicas de aprendizagem, as quais são definidas, em seu nível mais geral, como os "conhecimentos, capacidades, atitudes e valores necessários para que as pessoas sobrevivam, melhorem sua qualidade de vida e continuem aprendendo" (Coraggio, 1998, p. 86).

Como desdobramento da Conferência Mundial sobre Educação para Todos foi realizada em Salamanca/Espanha, em 1994, a Conferência Mundial de Educação Especial, quando foi construída e assinada pelos signatários a Declaração de Salamanca sobre Princípios, Política e Prática em Educação Especial, que se insere no contexto da disseminação das orientações neoliberais a serem efetivadas sob a forma de políticas públicas.

De acordo com a Declaração de Salamanca as escolas devem acolher todas as crianças e jovens, independentemente de suas condições físicas, intelectuais, sociais, emocionais, linguísticas ou outras. Crianças, jovens e adultos, cujas necessidades têm origem na deficiência ou em dificuldades cognitivas, devem ser incluídos em programas educacionais previstos para todos os educandos (Unesco,1994). 
Nessa perspectiva a escola deve promover uma educação de alta qualidade a todos os discentes, modificando atitudes discriminatórias, criando comunidades acolhedoras e desenvolvendo uma sociedade inclusiva. Precisa ser adaptada às necessidades dos alunos, respeitando os ritmos e os processos de aprendizagem. Deve contrapor-se à sociedade que inabilita e enfatiza os impedimentos, propondo uma pedagogia centrada nas potencialidades humanas (Unesco, 1994).

O Brasil entra em destaque nos últimos anos pelo avanço na criação de leis, diretrizes, decretos e políticas relacionados à garantia do direito de todos à educação. $O$ marco legal basilar é a Constituição Federal de 1988 (CF/1988), que no artigo 3º, inciso IV, propõe como um de seus princípios fundamentais "promover o bem de todos, sem preconceitos de origem, raça, sexo, cor, idade e quaisquer outras formas de discriminação" (Brasil, 1988, p. 5). Define, no artigo 205, a educação como direito de todos, garantindo o pleno desenvolvimento da pessoa, o exercício da cidadania e a qualificação para o trabalho. No artigo 206, inciso I, estabelece a "igualdade de condições de acesso e permanência na escola" e garante, como dever do Estado, no artigo 208, inciso III, a oferta do "atendimento educacional especializado, preferencialmente na rede regular de ensino" (Brasil, 1988, p. 35).

A CF/1988 garante a todos os alunos a frequência no ensino regular, com base no princípio de igualdade. Portanto, todo estudante tem direito a estar matriculado no ensino regular, e a escola tem o dever de matricular todos os educandos, não deixando que se discrimine qualquer pessoa em razão de sua deficiência ou sob qualquer outro pretexto.

Embora disciplinado na CF/1988 que a oferta do atendimento educacional fosse, preferencialmente, na rede regular de ensino, sinalizando para a promoção de uma educação inclusiva, em 1994, foi publicada a Política Nacional de Educação Especial, orientando o processo de "integração instrucional", que condiciona o acesso às classes comuns do ensino regular àqueles que "possuem condições de acompanhar e desenvolver as atividades curriculares programadas do ensino comum, no mesmo ritmo que os alunos ditos normais" (Brasil, 1994, p. 94). Assim, caso os aprendizes não conseguissem apresentar as condições estabelecidas para adequação ao sistema regular de ensino, eles seriam, então, encaminhados para a educação especial.

No que se refere à legislação relativa aos direitos do atendimento educacional à criança e ao adolescente, especialmente na Lei de Diretrizes e Bases da Educação, no artigo 58, "entende-se por educação especial, para efeitos desta Lei, a modalidade escolar, oferecida preferencialmente na rede de ensino, para educandos portadores de necessidades especiais" (Brasil, 1996, p. 27839). A referida lei decreta que a educação de pessoas com deficiência deve dar-se preferencialmente na rede regular de ensino, sendo dever do Estado e da família promovê-la.

A Convenção da Guatemala, em 1999, também foi um marco significativo para a educação inclusiva no Brasil, sendo promulgada pelo decreto n. 3.956/2001, o qual afirma que as pessoas com deficiência têm os mesmos direitos humanos e liberdades fundamentais que as demais pessoas, definindo como discriminação, com base na deficiência, toda diferenciação ou exclusão que possa impedir ou anular o exercício dos direitos humanos e de suas liberdades fundamentais (Brasil, 2001). A discriminação é compreendida como forma de diferenciação, restrição ou exclusão com base na deficiência. Vale salientar que esse decreto teve repercussão na educação, trazendo uma 
nova leitura ou interpretação da educação especial, das deficiências e da inclusão escolar na perspectiva de romper com as barreiras de acesso e permanência no processo de escolarização e no combate à discriminação social:

A trajetória de luta em busca da educação e principalmente da luta pelos seus direitos como cidadãos, apesar de suas deficiências, deve-se ao determinante papel exercido pelas instituições particulares e de caráter filantrópico. Foram estas que organizaram grandes movimentos pelos direitos das pessoas com deficiência e trouxeram para o eixo das discussões os direitos tão sonegados ao longo do tempo, denunciando a discriminação, o preconceito e a falta de programas educacionais básicos. (Fumegalli, 2012, p. 9)

O MEC criou, em 2003, o Programa educação inclusiva: direito à diversidade, visando a transformar os sistemas de ensino em sistemas educacionais inclusivos. Esse programa promove um amplo processo de formação de gestores e educadores nos municípios brasileiros para a garantia do direito de acesso de todos à escolarização, a organização do atendimento educacional especializado e a promoção da acessibilidade.

Outras iniciativas vieram ao longo dos anos 2000, como a Cartilha de acesso dos alunos com deficiência às escolas e classes comuns da rede regular, divulgada pelo Ministério Público Federal, a criação das normas e critérios para promoção da acessibilidade às pessoas com deficiência e mobilidade reduzida, a inclusão da língua brasileira de sinais como disciplina curricular na formação e certificação do professor, bem como a inclusão do tradutor ou intérprete de Libras para viabilizar a comunicação, a informação e a educação de alunos surdos na rede regular de ensino.

A Convenção sobre os Direitos das Pessoas com Deficiência, aprovada pela ONU em 2006, da qual o Brasil é signatário, estabeleceu que os Estados deveriam assegurar um sistema de educação inclusiva em todos os níveis de ensino, em ambientes que maximizem o desenvolvimento acadêmico e social compatível com a meta de inclusão plena. É assegurado, a partir dessa convenção, o direito de todos os alunos a frequentar o ensino regular, não podendo haver qualquer tipo de discriminação, sendo garantido também o apoio necessário para facilitar a aprendizagem do discente com deficiência. Esse apoio pode ser oferecido pelo atendimento educacional especializado, levando em consideração as necessidades específicas de cada educando.

O decreto n. 6.094/2007 estabeleceu, dentre as diretrizes do Compromisso Todos pela Educação, a garantia do acesso e permanência no ensino regular e o atendimento às necessidades educacionais especiais dos estudantes, fortalecendo a inclusão educacional nas escolas públicas.

A Política Nacional de Educação Especial na Perspectiva da Educação Inclusiva, de janeiro de 2008, estabeleceu que a educação especial fosse uma modalidade de ensino que perpassa todos os níveis: da educação básica ao ensino superior. Além disso, definiu o AEE como sendo o conjunto de atividades, recursos de acessibilidade e pedagógicos institucionalmente prestados de forma complementar ou suplementar à formação dos alunos no ensino regular. Também prevê como ação do MEC a formação de professores e gestores para educação inclusiva, as adaptações arquitetônicas das escolas e a produção e distribuição de recursos para a acessibilidade. 
A inclusão de aprendizes com necessidades especiais no sistema regular de ensino é hoje a diretriz principal das políticas públicas educacionais, tanto a nível federal, quanto estadual e municipal (Ferreira, 2004; Ferreira; Glat, 2003). Educação inclusiva, entendida sob a dimensão didático-curricular, é aquela que proporciona ao aluno com necessidades educativas especiais participar das atividades cotidianas da classe regular, aprendendo as mesmas coisas que os demais - mesmo que de modos diferentes, preferencialmente sem defasagem idade-série. Como agente mediador do processo ensino-aprendizagem, cabe ao professor o papel de fazer as adaptações necessárias no currículo escolar (Glat et al., 2003).

Um novo paradigma nasceu com essa forma de se pensar a escola. Portanto, uma nova escola a qual está em processo de construção é definida como inclusiva. Para Mittler (1999) a escola inclusiva só começa com uma radical reforma da instituição escolar e com a mudança do sistema existente, repensando-se inteiramente o currículo para alcançar as necessidades de todos. Em outras palavras, a promoção da educação inclusiva não representa simplesmente transferir o discente da escola especial para a escola regular, pois ela requer uma mudança na mente e nos valores da escola, daí a importância da formação docente, da discussão e da ação de todos da comunidade escolar: "Talvez a formação docente para Educação Inclusiva não nos conduza inexoravelmente a ela, mas por certo nos vai ajudar a vê-la cada vez mais perto e desta forma promover a justiça e os direitos para todos os alunos" (Rodrigues, 2006, p. 14).

Nesse sentido, tanto a esfera governamental, quanto a acadêmica devem atuar em cooperação na promoção da formação e capacitação de professores e demais agentes educacionais, bem como na produção de conhecimento por meio de pesquisas e projetos que validem e disseminem ações educativas bem-sucedidas que atendam a essa nova proposta.

Apesar de toda essa trajetória histórica dos documentos legais que amparam e disciplinam a educação inclusiva no Brasil a escola inclusiva ainda está em seu estado embrionário, há uma lacuna entre a legislação e a realidade das escolas regulares. $O$ número de alunos incluídos tem triplicado nos últimos anos, porém o preconceito e a falta de conhecimento das leis que os amparam e beneficiam ainda deixam um grande contingente de indivíduos com deficiência fora da escola regular. Além disso, os aprendizes com deficiências que estão frequentando a escola regular sofrem com a segregação e com o despreparo dos professores para lidarem com as especificidades e as necessidades de atendimento educacional.

A construção de políticas de atenção diferenciadas no ensino regular pode provocar um impacto significativo para o uso de novas abordagens pedagógicas no processo de inclusão escolar, portanto, é urgente a ampliação das oportunidades de formação docente em educação inclusiva.

\section{A inserção do campo temático da educação inclusiva nos encontros de formação do pacto: caminhos para o fortalecimento do ensino médio}

Atualmente assiste-se a avanços e muitos impasses legais. Os argumentos da diferença, da preocupação com o outro, do respeito, da aceitação, do reconhecimento e 
da tolerância trazem para o eixo das discussões os direitos tão sonegados ao longo do tempo, denunciando a discriminação, o preconceito e a falta de programas de formação de professores que contemplem a educação inclusiva em seus documentos oficiais:

Percebe-se que atitudes discriminatórias persistem na sociedade devido à falta de informação e/ou inexperiência, da convivência com o diferente. A resposta educativa à diversidade e à igualdade em educação são, sem dúvida, um dos desafios mais importantes da atualidade. Alcançar os objetivos da prática educativa requer trocas nas concepções, atitudes e envolvimento de todo o quadro docente e, principalmente, das instituições governamentais, em âmbito de políticas sociais e econômicas, fazendo com que a realidade do princípio da educação seja, realmente, responsabilidade de todos. (Fumegalli, 2012, p. 32)

A proposta do pacto entre MEC, governos estaduais e distrital tem como uma de suas principais ações formar, em nível de aperfeiçoamento ou extensão, todos os professores e coordenadores que atuam no ensino médio com vista à valorização dos profissionais da educação, a partir do diálogo entre os conhecimentos teóricos e experiências docentes de gestão pedagógica (Brasil, 2014a). Conforme o documento orientador das ações e de formação docente do Pacto Nacional pelo Fortalecimento do Ensino Médio essa proposta busca elevar o padrão de qualidade do ensino médio brasileiro, em suas diferentes modalidades, orientado pela perspectiva de inclusão de todos que a ela têm direito. Porém, há controvérsias na efetivação dessa proposta, pois a educação inclusiva não aparece como campo temático no processo de formação docente, ou seja, não é dada a devida formação para promover a inclusão de alunos com necessidades especiais nas classes regulares do ensino médio.

$\mathrm{Na}$ estruturação e organização do curso, o eixo central do processo formativo dos professores e coordenadores pedagógicos do ensino médio é o desenvolvimento da temática Sujeitos do ensino médio e formação humana integral, que orienta a discussão e o trabalho em todas as etapas. Essa temática, apesar de abranger a formação integral não faz referência à modalidade da educação especial na perspectiva inclusiva. Em seus tópicos de discussão, o projeto de formação humana integral propõe-se

a superar a dualidade presente na organização do ensino médio, promovendo o encontro sistemático entre 'cultura e trabalho', fornecendo aos alunos uma educação integrada ou unitária capaz de propiciar-lhes a compreensão da vida social, 'da evolução técnico-científica, da história e da dinâmica do trabalho'. (Cury, 1991, p. 24)

A formação humana igualitária e integral para todos que ora se anuncia no eixo central da proposta do pacto e está presente no caderno / de formação de professores não aborda a temática da educação inclusiva, reforçando as dificuldades dos educadores em refletir e repensar a respeito das práticas pedagógicas inclusivas. A ausência dessa abordagem na formação docente aumenta o eco dos professores quanto à alegação do despreparo para a atuação com pessoas deficientes: "É uma realidade que não pode ser ignorada, é comum ouvir de professores que eles não foram preparados para isto ou não 
fizeram essa opção" (Cavalcante, 2004; Mantoan, 2004 apud Castro, 2003, p. 6). O medo desses profissionais está ligado à ausência de conhecimentos necessários para lidarem com as limitações, o que gera, nos docentes, resistência ou rejeição em relação à inclusão.

Além do eixo central do processo de formação de professores o pacto é organizado em duas etapas distintas: na primeira etapa, de acordo com o documento orientador (Brasil, 2014), o conjunto de temas apresentados fundamenta-se nas Diretrizes Curriculares Nacionais do Ensino Médio e abrange as seguintes abordagens: sujeito do ensino médio e formação humana integral; ensino médio, currículo, organização e gestão do trabalho pedagógico; avaliação; áreas de conhecimento e integração curricular. A segunda etapa apresenta uma reflexão das áreas de conhecimento e das relações entre elas e seus componentes curriculares como matriz de referência para construção dos direitos à aprendizagem e ao desenvolvimento:

A formação humana integral deve garantir ao adolescente, ao jovem e ao adulto o direito às condições necessárias para a leitura do mundo e para a atuação como cidadão pertencente a um país e integrado dignamente à sociedade. Formação que, neste sentido, supõe a compreensão das relações sociais subjacentes a todos os fenômenos e, também, à diversidade dos sujeitos que freqüentam ou têm direito de acessar o Ensino Médio brasileiro. (Ciavatta, 2005, p. 85)

O Pacto Nacional pelo Fortalecimento do Ensino Médio aponta para a superação da fragmentação e do pragmatismo, defendendo uma educação integrada entre trabalho, ciência, tecnologia e cultura. À luz das Diretrizes Curriculares do Ensino Médio designa as formas de ofertas e organização, indicando que:

IX - os componentes curriculares devem propiciar a apropriação de conceitos e categorias básicas, e não o acúmulo de informações e conhecimentos, estabelecendo um conjunto necessário de saberes integrados e significativos;

$[\ldots]$

XI - a organização curricular do Ensino Médio deve oferecer tempos e espaços próprios para estudos e atividades que permitam itinerários formativos opcionais diversificados, a fim de melhor responder à heterogeneidade e pluralidade de condições, múltiplos interesses e aspirações dos estudantes, com suas especificidades etárias, sociais e culturais, bem como sua fase de desenvolvimento;

XII - formas diversificadas de itinerários podem ser organizadas, desde que garantida a simultaneidade entre as dimensões do trabalho, da ciência, da tecnologia e da cultura, e definidas pelo projeto político-pedagógico, atendendo necessidades, anseios e aspirações dos sujeitos e a realidade da escola e do seu meio. (Brasil, 2012, p. 6)

Apesar de compreender a importância do redesenho curricular e das discussões sobre o papel de cada saber disciplinar particular e sua articulação com outros saberes - a interdisciplinaridade e a transdisciplinaridade -, a formação de professores do ensino médio deve ir além dos componentes curriculares e suas áreas de conhecimento. Deve abrir-se para os novos saberes, os novos estudantes e as outras formas de ensinar, aprender e avaliar a aprendizagem. Não se pode fazer inclusão quando não se consegue sequer incluir o campo temático da educação inclusiva no programa de formação docente: 
O sucesso da aprendizagem está em explorar talentos, atualizar possibilidades, desenvolver predisposições naturais de cada aluno. As dificuldades e limitações são reconhecidas, mas não conduzem/ restringem o processo de ensino, como comumente acontece. (Mantoan, 2003, p. 42)

Neste caso o professor desempenha um papel bem relevante nesse processo, tendo claro que a inclusão do aluno deficiente no ensino regular não acontece como num passe de mágica. Os profissionais da educação precisam estar atentos às particularidades dos educandos com deficiência, empregando estímulos corretos e úteis para o seu desenvolvimento físico, psíquico e cognitivo, respeitando-os e atendendo-os como cidadãos capazes, detentores dos mesmos direitos que os demais alunos:

Trabalhar os professores para a nova realidade de inclusão, através de palestras, oficinas ou trocas de experiências entre profissionais é fundamental. Transmitir-Ihes informação, conhecimento, desenvolver habilidades e incentivar atitudes; como tratar, falar ou não da deficiência, oferecer ou não ajuda, Linguagem Brasileira de Sinais (Libras), acessibilidade, enfim, o dia a dia e o convívio com as diferenças em sala de aula são fundamentais. (Fumegalli, 2012, p. 40)

É nesse processo que o professor pode ver e rever sua prática pedagógica, as estratégias aplicadas na aprendizagem dos alunos, os erros e acertos desse processo para melhor definir, retomar e modificar o seu fazer de acordo com as necessidades dos discentes. A reestruturação do programa de formação docente do Pacto Nacional pelo Fortalecimento do Ensino Médio é uma estratégia indispensável a ser enfrentada a fim de assegurar efetivamente a concretização do direito a todos os educandos de aprenderem na escola.

\section{Considerações finais}

Ao pesquisar o alcance dos fundamentos legais da política de educação especial na perspectiva inclusiva, confrontando com as possibilidades e os limites da formação e atuação do trabalho docente no ensino médio propostos no referido pacto, foi possível perceber que a LDB é clara ao definir a educação especial como uma modalidade de educação escolar e ao conferir que os indivíduos com necessidades especiais educandos com deficiência, transtornos globais do desenvolvimento e altas habilidades ou superdotação - devem ter assegurados o acesso à educação escolar, preferencialmente na rede regular de ensino. Para tanto, o sistema de ensino deve oferecer currículos, práticas educativas, espaços, recursos e tempos de aprendizagens que atendam às necessidades dos diferentes níveis e modalidades de ensino, assim como a cada faixa etária.

No entanto, o programa de formação docente do Pacto Nacional pelo Fortalecimento do Ensino Médio, apesar de sua amplitude de alcance, não orienta os sistemas estaduais e municipais na condução das escolas na elaboração de suas propostas curriculares ao não ofertar o campo temático da educação inclusiva em seu material didático limita as discussões dos professores ao nível do senso comum. Com isso restringe o acesso ao conhecimento científico, e a formação continuada tende a não gerar aprofundamento e atualização adequada a respeito da educação inclusiva.

Regae: Rev. Gest. Aval. Educ. Santa Maria

\begin{tabular}{l|l|l|}
11 & Jan./abr. 2017 & p. $69-84$
\end{tabular} 
Portanto, como as escolas podem receber, acolher, conhecer e planejar o atendimento às necessidades especiais dos alunos sem o devido preparo de professores e coordenadores pedagógicos? É necessário repensar, avaliar e reconduzir a proposta de formação docente do Pacto Nacional pelo Fortalecimento do Ensino Médio na perspectiva de inserção do campo temático da educação inclusiva em seu programa oficial, a fim de atender legalmente ao direito inalienável de todos à educação.

O pacto pode ser um dos caminhos para o reconhecimento da educação inclusiva como forma prioritária de atendimento aos estudantes com necessidades educativas especiais. Na prática esse modelo ainda não se configura no país como uma proposta educacional amplamente difundida e compartilhada, daí a importância da formação docente em direção a uma ruptura com o modelo de educação segregada e excludente.

\section{Referências}

AUSTIN, Priscila; KAMINSKI, Walkiria. Um beija-flor em minha vida: aprendendo a lidar com pessoas especiais. Educação Especial e Inclusiva. Fortaleza: IPDH, 2007.

BRASIL. Câmara dos Deputados. Plano Nacional de Educação. Brasília, DF, 2000. Disponível em: <http://www.câmara.gov.br>. Acesso em: 7 fev. 2015.

BRASIL. Conselho Nacional de Educação. Câmara de Educação Básica. Resolução n. 2, de 30 de janeiro de 2012. Define diretrizes curriculares nacionais para o ensino médio. Diário [da] República Federativa do Brasil, Brasília, DF, 31 jan. 2012. Seção 1, n. 22, p. 20-21.

BRASIL. Declaração de Salamanca e linha de ação sobre necessidades educativas especiais. Brasília: Unesco, 1994a. Disponível em <http://portal.mec.gov.br/seesp/arquivos/pdf/salamanca.pdf>. Acesso em 4 fev. 2015.

BRASIL. Declaração mundial sobre educação para todos: plano de ação para satisfazer as necessidades básicas de aprendizagem. Brasília: Unesco: Jomtien, 1990. Disponível em <http://www.unicef.org/brazil/pt/resources 10230.htm>. Acesso em 7 fev. 2015.

BRASIL. Decreto n. 6.094, de 24 de abril de 2007. Dispõe sobre a implementação do Plano de Metas Compromisso Todos pela Educação. Diário [da] República Federativa do Brasil, Brasília, DF, 25 abr. 2007. Disponível em <http://www.planalto.gov.br/ccivil 03/ ato20072010/2007/decreto/d6094.htm>. Acesso em 8 fev. 2015.

BRASIL. Lei n. 9.394, de 20 de dezembro de 1996. Estabelece as Diretrizes e Bases da Educação Nacional. Diário Oficial da República Federativa do Brasil. Brasília, DF, 23 dez. 1996. Seção 1, p. 27.833-27.841.

BRASIL. Referenciais para a formação de professores. Brasília: MEC, 1999.

BRASIL. Formação de professores do ensino médio, etapa I - caderno I: ensino médio e formação humana integral. Curitiba: UFPR/Setor de Educação, 2013a. Disponível em $<$ http://pactoensino medio.mec.gov.br/index.php?option=com content\&view=category\&id=13\&ltemid=117>. Acesso em 5 fev. 2015.

BRASIL. Pacto nacional pelo fortalecimento do ensino médio: documento orientador das ações de formação continuada de professores e coordenadores do Ensino Médio. Brasília: MEC, 2014a. Disponível em $<$ http://pactoensinomedio.mec.gov.br/images/pdf/documento orientador.pdf $>$. Acesso em 5 fev. 2015. 
BRASIL. Diretrizes nacionais para a educação especial na educação básica. Brasília: MEC/Seesp, $2002 . \quad$ Disponível em $<$ http://portal.mec.gov.br/seesp/arquivos/pdf/diretrizes.pdf>. Acesso em 4 fev. 2015.

BRASIL. Política nacional de educação especial. Brasília: MEC/Seesp, 1994b.

BRASIL. Política nacional de educação especial na perspectivada educação inclusiva. Brasília: MEC, $2008 . \quad$ Disponível em $<$ http://portal.mec.gov.br/arquivos/pdf/politicaeducespecial.pdf>. Acesso em 10 fev. 2015.

BRASIL. Portaria n. 1.140, de 22 de novembro de 2013. Institui o Pacto Nacional pelo Fortalecimento do Ensino Médio. Diário Oficial da República Federativa do Brasil. Brasília, DF, 25 nov. 2013b. Seção 1, n. 228, p. 24-25.

BRASIL. Presidência da República. Casa Civil. Subchefia para Assuntos Jurídicos. Decreto n. 3.956, de 8 de outubro de 2001. Promulga a Convenção Interamericana para a Eliminação de Todas as Formas de Discriminação contra as Pessoas Portadoras de Deficiência. Diário Oficial [da] República Federativa do BRASIL. Brasília, DF, 9 out. 2001. Disponível em <http://www.planalto.gov.br/ccivil 03/decreto/2001/d3956.htm>. Acesso em 10 fev. 2015.

BRASIL. Plano nacional de educação. Brasília, 2014b. Disponível em $<$ http://www.planalto.gov.br/CCIVIL 03/ Ato2011-2014/2014/Lei/L13005.htm>. Acesso em 7 fev. 2015

BRASIL. Senado Federal. Constituição da República Federativa do Brasil: texto promulgado em 5 de outubro de 1988. Brasília, 1988. Disponível em <http://www.senado. gov.br/legislacao/const/con1988/CON1988 05.10.1988/CON1988.pdf>. Acesso em 13 jul. 2015.

BUENO, José Geraldo Silveira. Crianças com necessidades educativas especiais, política educacional e a formação de professores: generalistas ou especialistas. Revista Brasileira de Educação Especial, Rio de Janeiro v. 3, n. 5,1998, p. 7-25.

CASTRO, Raimundo Márcio Mota de. O professor e sua formação diante da educação inclusiva. CONGRESSO NACIONAL DE EDUCAÇÃO DA PUCPR, 8, 2008, Curitiba. Anais... 2008. Curitiba: PUCPR, 2008. Disponível em <http://www.pucpr. br/eventos/educere/educere2008/anais/pdf/740_481.pdf>. Acesso em 13 jul. 2015.

CIAVATTA, Maria. A formação integrada: a escola e o trabalho como lugares de memória e de identidade. In: CIAVATTA, Maria; FRIGOTTO, Gaudêncio; RAMOS, Marise (org.). Ensino médio integrado: concepção e contradições. São Paulo: Cortez, 2005, p. 83-105.

CORAGGIO, José Luis. Propostas do Banco Mundial para a educação: sentido oculto ou problemas de concepção? In: TOMMASI, Lívia de et al (org.). O Banco Mundial e as políticas educacionais. São Paulo: Cortez, 1998, p. 75-121.

CRUZ, Priscila; MONTEIRO, Luciano (org.). Anuário brasileiro de educação básica. São Paulo: Moderna, 2013.

CURY, Carlos Roberto Jamil. Alguns apontamentos em torno da expansão e qualidade do ensino médio no BRASIL. Ensino médio como educação básica. In: MEC/Seneb/Pnud, Ensino médio como educação básica. Cadernos Seneb, n. 4. São Paulo: Cortez; Brasília: Seneb, 1991, p. 45-62.

DOURADO, Luiz Fernandes (org.). Políticas públicas e educação básica. São Paulo: Xamã,2001. 
FERREIRA, Júlio Romero; GLAT, Rosana. Reformas educacionais pós-LDB: a inclusão do aluno com necessidades especiais no contexto da municipalização. In: SOUZA, Donaldo Bello de; FARIA, Lia Ciomar Macedo de (org.). Descentralização, municipalização e financiamento da educação no Brasil pós-LDB. Rio de Janeiro: DP\&A, 2003, p. 372-390.

FERREIRA, Maria Cristina Costa. Formação de professores. In: MENDES, Enicéia Gonçalves et al (org.). Temas em educação especial: tendências atuais. São Carlos: UFSCar, 2004, p. 251-256.

FUMEGALLI, Rita de Cássia de Ávila. Inclusão escolar: o desafio de uma educação para todos? ljuí: Unijuí, 2012. 47f. Monografia (especialização em Educação Especial: Deficiência Mental e Transtorno). Departamento de Humanidades e Educação, Universidade Regional do Noroeste do Estado do Rio Grande do Sul.

GARCIA, Rosalba Maria Cardoso. Política de educação especial na perspectiva inclusiva e a formação docente no Brasil. Revista Brasileira de Educação, Rio de Janeiro, v. 18, n. 52, 2013, p. 101-119.

GATTI, Bernadete. A análise das políticas públicas para formação continuada no Brasil, na última década. Revista Brasileira de Educação, Rio de Janeiro, v.13, n. 37, 2008, p. 57-70.

GLAT, Rosana et al. Panorama nacional da educação inclusiva no Brasil: relatório de consultoria técnica, projeto educação inclusiva no Brasil. Brasília: Banco Mundial, 2003.

LIBÂNEO, José Carlos. Democratização da escola pública: a pedagogia crítica-social dos conteúdos. São Paulo: Loyola, 1989.

MANTOAN, Maria Teresa Eglér. Inclusão escolar: o que é? por quê? como fazer? São Paulo: Moderna, 2003.

MITTLER, Peter. Educando para a inclusão. Revista Educação Brasileira, Brasília: Crub, v. 21, n. 43,1999 , p. $43-63$.

ORGANIZACAO DAS NAÇÕES UNIDAS. Convenção sobre os direitos das pessoas com deficiência. Nova lorque: ONU, 2006. Disponível em: $<$ http://www.planalto.gov.br/ccivil 03/ ato2007-2010/2009/decreto/d6949.htm>. Acesso em: 15 fev. 2015.

RODRIGUES, David (org.). Inclusão e educação: doze olhares sobre a educação inclusiva. São Paulo: Summus, 2006.

UNESCO. Declaração de Salamanca e linha de ação sobre as necessidades educativas especiais. Brasília: Unesco, 1994.

Karlane Holanda Araújo é estudante do curso de doutorado em Educação Brasileira na Universidade Federal do Ceará. Mestre em Educação Brasileira pela Universidade Federal do Ceará, especialista em Gestão e Avaliação da Escola Pública pela Universidade Juíz de Fora e em Educação Especial pela Universidade Vale do Acaraú. Professora na rede estadual de ensino do Ceará desde 2004. Bolsista da Fundação Cearense de Apoio ao Desenvolvimento Científico e Tecnológico.

Endereço: Rua Nove, 92/1032, bl. c - 61635-270 - Caucaia - CE- Brasil.

E-mail: karlaneufc@gmail.com. 
José Melinho de Lima Neto é estudante do curso de doutorado em Educação Brasileira no Programa de Pós-Graduação em Educação da Universidade Federal do Ceará. Mestre em Educação Brasileira e professor efetivo na educação básica do município de Pacajus - CE.

Endereço: Rua Papi Júnior, 2406 - 60441-700 - Fortaleza - CE - Brasil.

E-mail: j.mlneto@outlook.com.

Recebido em 20 de julho de 2015.

Aceito em 12 de outubro de 2016. 